\title{
Astenia y Adinamia
}

\section{Asthenia and Adynamia}

\author{
Alfredo Pinzón-Junca • Bogotá, D.C. (Colombia)
}

DOI: https://doi.org/10.36104/amc.2021.2523

Es frecuente el uso simultáneo de los términos astenia y adinamia en la anamnesis de los pacientes, como si se tratase de dos síntomas diferentes. Los significados de estos sintagmas, registrados en los diccionarios general y de términos médicos de la Real Academia Española, ayudan a disipar esta confusión:

Astenia: (Del griego ỏoféveı $\alpha$ asthéneia 'debilidad', 'falta de fuerza') (reintroducida y documentada en francés desde 1790) [inglés: asthenia]:

1) s.f. Sensación intensa de falta generalizada de fuerza.

2) f. Med. Falta o decaimiento de fuerzas caracterizado por apatía, fatiga física o ausencia de iniciativa.

Obs.: Los términos "astenia", "cansancio", "fatiga" y "debilidad" se usan con frecuencia en forma intercambiable, como si fueran sinónimos.

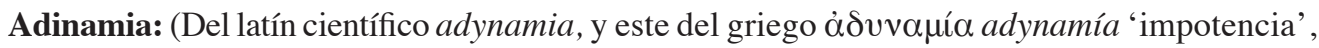
'debilidad física') [inglés: adynamia]:

1) s.f. Disminución extrema de la actividad muscular, que impide los movimientos del enfermo.

2) f.Med. Extremada debilidad muscular que impide los movimientos del enfermo.

3) Dificultad o ausencia de la iniciación de una acción o un movimiento.

4) Postración completa física y moral, falta o pérdida de la fuerza.

Obs.: En propiedad, el término "adinamia" implica mayor grado de disminución que la simple "hipodinamia".

Etimológicamente, estos dos síntomas, provenientes del griego, utilizan el prefijo alfa privativo $a$ - ['no', 'sin'] unido a la raíz sthénos [〈vigor〉, 〈fuerza〉, 〈poder〉] en el primer caso, y dynamis ['fuerza', 'movimiento', 'potencia'] en el segundo, y el sufijo de cualidad -ia, ['estado'], por lo que en realidad su significado es similar y son términos equiparables. No obstante, algunos textos y diccionarios promueven separar el uso de astenia para referirse al cansancio o debilidad muscular que no mejora con el reposo y reservar adinamia para expresar la disminución o ausencia de movimiento o reacción. En ambos casos pueden obedecer a causas orgánicas, funcionales, psiquiátricas o psicológicas.

Por lo tanto, puede ser redundante expresar en la misma oración los dos términos (astenia y adinamia) o sus correlatos en español, y se aconseja evitar este pleonasmo.

\section{Fuentes:}

- Diccionario de la Real Academia Española de la Lengua, disponible en: www.rae.es

- Real Academia Nacional de Medicina. Diccionario de Términos Médicos. Editorial Médica Panamericana. 2012

- Diccionario Médico. Clínica Universidad de Navarra, disponible en: www.cun.es

* Envíe sus inquietudes, sugerencias o comentarios a: contacto@actamedicacolombiana.com - alfpin@hotmail.com Dr. Alfredo Pinzón-Junca: Especialista en Medicina Interna y Psicoanálisis, Hospital Simón Bolívar. Bogotá DC (Colombia). 